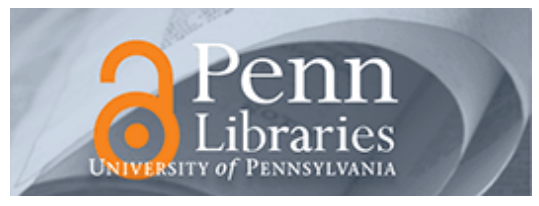

University of Pennsylvania ScholarlyCommons

9-2009

\title{
Commentary-The Stock Market's Pricing of Customer Satisfaction
}

Christopher D. Ittner

University of Pennsylvania

David F. Larcker

Daniel J. Taylor

University of Pennsylvania

Follow this and additional works at: https://repository.upenn.edu/accounting_papers

Part of the Accounting Commons, Marketing Commons, and the Sales and Merchandising Commons

\section{Recommended Citation}

Ittner, C. D., Larcker, D. F., \& Taylor, D. J. (2009). Commentary-The Stock Market's Pricing of Customer Satisfaction. Marketing Science, 28 (5), 826-835. http://dx.doi.org/10.1287/mksc.1090.0526

This paper is posted at ScholarlyCommons. https://repository.upenn.edu/accounting_papers/26

For more information, please contact repository@pobox.upenn.edu. 


\title{
Commentary-The Stock Market's Pricing of Customer Satisfaction
}

\author{
Abstract \\ A number of recent marketing studies examine the stock market's response to the release of American \\ Customer Satisfaction Index (ACSI) scores. The broad purpose of these studies is to investigate the stock \\ market's valuation of customer satisfaction. However, a key focus is on whether customer satisfaction \\ information predicts long-run returns. We provide evidence on the market's pricing of ACSI information \\ using a more comprehensive set of well-established tests from the accounting and finance literatures. We \\ find that ACSI scores provide some incremental information on future operating income and that the \\ market quickly responds to the release of information on large increases in satisfaction. However, we find \\ no evidence that ACSI predicts long-run returns. These results suggest that customer satisfaction \\ information is value relevant, but they are also consistent with Jacobson and Mizik's conclusion \\ [Jacobson, R., N. Mizik. 2009. The financial markets and customer satisfaction: Reexamining possible \\ financial market mispricing of customer satisfaction. Marketing Sci. 28(5) 810-819] that mispricing of \\ ACSI information, if present at all, is limited.

\section{Keywords} \\ customer loyalty, econometrics, stock valuation \\ Disciplines \\ Accounting | Marketing | Sales and Merchandising
}




\section{Rock Center for Corporate Governance WORKING PAPER SERIES}

\begin{tabular}{|c||}
\hline The Stock Market's Pricing of Customer \\
Satisfaction \\
Rock Center for Corporate Governance \\
Working Paper No. 62 \\
Christopher D. Ittner \\
University of Pennsylvania - Accounting Department \\
David F. Larcker \\
Stanford University - Graduate School of Business \\
Daniel J. Taylor \\
Stanford University - Graduate School of Business \\
June 16, 2009 \\
\hline \hline
\end{tabular}

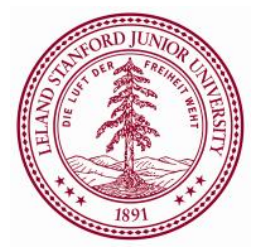

\section{The Rock Center for Corporate Governance}

STANFORD UNIVERSITY

A joint initiative of Stanford Law School and the Graduate School of Business

Crown Quadrangle • 559 Nathan Abbott Way • Stanford, CA 94305 rockcenter@law.stanford.edu • http://rockcenter.stanford.edu 


\title{
The Stock Market's Pricing of Customer Satisfaction
}

\author{
Christopher D. Ittner \\ ittner@,wharton.upenn.edu \\ The Wharton School \\ University of Pennsylvania \\ 1300 Steinberg-Dietrich Hall \\ Philadelphia, PA 19104 \\ David F. Larcker \\ dlarcker@stanford.edu \\ Daniel Taylor \\ djtaylor@stanford.edu \\ Stanford University \\ Graduate School of Business \\ 518 Memorial Way \\ Stanford, CA 94305-5015
}

June 16, 2009

The financial support of Ernst \& Young (Ittner) and the Deloitte Foundation (Taylor) is greatly appreciated. 


\title{
The Stock Market's Pricing of Customer Satisfaction
}

\begin{abstract}
A number of recent marketing studies examine the stock market's response to the release of American Customer Satisfaction Index (ACSI) scores. The broad purpose of these studies is to investigate the stock market's valuation of customer satisfaction. However, a key focus is on whether customer satisfaction information predicts long-run returns. We provide evidence on the market's pricing of ACSI information using a more comprehensive set of well-established tests from the accounting and finance literatures. We find that ACSI scores provide some incremental information on future operating income and that the market quickly responds to the release of information on large increases in satisfaction. However, we find no evidence that ACSI predicts long-run returns. These results suggest that customer satisfaction information is value-relevant, but are also consistent with Jacobson and Mizik's (2009) conclusion that mispricing of ACSI information, if present at all, is limited.
\end{abstract}




\section{The Stock Market’s Pricing of Customer Satisfaction}

\section{Introduction}

Recent marketing research has emphasized the stock market's valuation of customer satisfaction. This emphasis is not surprising given the potential economic benefits from higher satisfaction (such as customer retention and loyalty, price tolerance, word of mouth recommendations, etc.) and claims that stock market participants do not accurately impound customer satisfaction and other marketing information in share prices. Researchers' ability to study the market's pricing of customer satisfaction has been greatly aided by the development of the American Customer Satisfaction Index (ACSI), which provides a novel dataset that uses a common methodology to collect customer satisfaction data for a broad cross-section of major U.S. companies. These data give researchers the unique ability to link the release of a standard set of non-mandated, firm-level marketing information to publicly-available operating and stock market performance measures.

Studies examining this link have largely concentrated on the stock market's short-term response to the release of new ACSI scores and/or investors' ability to use the ACSI to earn abnormal long-run stock returns. Fornell et al. (2006), for example, conclude that the market does not respond to ACSI scores at their release, but that a trading rule based on the ACSI data can produce substantial long-run returns. Aksoy et al. (2008) examine whether the "mispricing" of ACSI information identified by Fornell et al. (2009) is an artifact of risk differences, and again conclude that the ACSI can be used to earn substantial abnormal long-run stock returns, a result consistent with market mispricing. In contrast, the current study by Jacobson and Mizik (2009) 
finds relatively little ability of the ASCI to predict long-run abnormal stock returns (with the potential exception of a small set of internet firms).

Given the mixed results in these studies and their differences in research methodologies and choices (some of which are unusual), we provide another examination of the stock market's pricing of ACSI information using well-established econometric methods from the accounting and finance literatures. In contrast to the piecemeal approaches used in prior studies, we take a more comprehensive look at the valuation of ACSI scores. We begin by examining whether the ACSI is associated with future firm operating performance (revenues, profit margins, and operating income). If ACSI predicts future operating performance, then in an efficient market we expect stock prices to react to unexpected component of ACSI. We then re-examine the market's short-term response to the release of ACSI information. If the market prices ACSI in an efficient manner, then we expect a quick adjustment to the new information, in which case ACSI will predicts short-run returns. Finally, we use more typical investor expectation models and portfolio formation rules from the accounting and finance literatures to investigate the ability to use ACSI information to earn abnormal long-run stock returns. If the market misprices ACSI, then we expect a delayed adjustment to new information, in which case ACSI will predict long-run returns.

Analyses using this broader set of tests suggest that the ACSI has incremental ability to predict future operating performance (which should be the key input into market valuation) and that large, unexpected ACSI improvements are associated with substantial short-term announcement period abnormal returns. However, we find that ACSI appears to be quickly impounded into stock prices by the market and does not predict long-term abnormal returns. Consistent with the studies by Fornell et al. (2006) and Aksoy et al. (2008), these results suggest 
that the market does value ACSI information, but the significant announcment period response to the release of new ACSI scores, together with the lack of significant long-run abnormal returns, are more consistent with Jacobson and Mizik's (2009) conclusion that the mispricing of ACSI information is limited.

\section{Background}

Concluding that the market has mispriced new, value-relevant information requires three conditions to hold. First, the information being released must provide an unexpected, incremental signal about future operating performance (or discount rates) that is not available from existing information. ${ }^{1}$ Even if improvements in certain customer satisfaction attributes lead to higher future operating performance in individual firms (as many studies have found), a common measure such as the ACSI may not be a valid indicator of customer satisfaction across a broad sample of firms. Unless the ACSI is incrementally predictive of subsequent operating performance (above current operating performance) in the sample used in the study, any finding of an association between the release of ACSI scores and stock market returns is questionable.

Second, even if the ACSI provides incremental information on future operating performance, these benefits must not be (fully) anticipated by the market. ${ }^{2}$ In this regard it is the unexpected component of ACSI that will be priced by the market. As Jacobson and Mizik (2009)

\footnotetext{
${ }^{1}$ In a frictionless market, stock price is equal to the present value of future cash flows.

${ }^{2}$ For example, ACSI levels are highly autocorrelated and the new scores may already be anticipated by the market. Tuli and Bharadwaj (forthcoming) report that ACSI scores from 1994 to 2006 have a time series correlation of 0.91 $(p<0.001)$ from one year to the next. Given this significant autocorrelation, existing satisfaction levels may already allow the market to anticipate any future operating performance implications and accurately impound expectations about these benefits in current stock prices. Consequently, the new scores may be expected and their release may not provide incremental information or affect stock returns, even though higher customer satisfaction scores provide economic benefits.
} 
note, the efficient markets hypothesis argues that stock market participants quickly and efficiently impound all available information into their expectations of future cash flows, and therefore into stock prices. According to this perspective, the release of new information such as ACSI updates may be value-relevant and move the market in the short-term, but investors should not be able to use this information to achieve long-term abnormal returns. Thus, mispricing implies that the new information is not fully impounded into stock price at its release.

Third, if significant mispricing has occurred, the accounting and finance literatures argue that trading rules based on new, unexpected information should allow informed traders to earn positive longer-term risk-adjusted returns based upon their superior knowledge of the information's ultimate value implications. Such "market anomalies" occur when market participants do not accurately assess the future financial implications of the new information and informed traders lack sufficient capital to arbitrage away the mispricing.

Absent all three of these conditions, empirical studies may find significant associations between marketing measures such as the ACSI and operating or stock market performance, but their piecemeal results make it difficult to conclude that the information is or is not mispriced by the market. Jacobson and Mizik (2009), as well as the study by Aksoy et al. (2008), focus on the third condition without examining whether the ACSI measures in their sample actually provide incremental information on future operating performance or whether the market responds to unexpected innovations in ACSI measures when they initially are released. ${ }^{3}$ Fornell et al. (2006) examine the market's short-term response to the release of ACSI information, finding no evidence that the market responds to the release of new ACSI measures, but provide some

\footnotetext{
${ }^{3}$ Aksoy et al. (2008) report similar accounting returns (return on assets and return on equity) in (1) firms with above average ACSI levels and increasing ACSI scores, and (2) firms with above average ACSI levels but declining scores. However, they do not examine whether ACSI measures are leading indicators of these financial measures, and focus their long-run valuation tests on the first set of firms.
} 
evidence that the market responds to the ACSI in the long term. Aksoy et al. (2008) rely on Fornell et al.'s (2006) insignificant, short-term event study evidence in their justification for focusing on long-term mispricing of ACSI information, assuming that (in the short-term) the market does not accurately or efficiently react to the release of new information. They do not examine the short-term market response to the release of new ACSI information in their sample. None of the preceding studies examines the association between current ACSI and future operating performance, or whether all three conditions hold in a single sample. These limitations raise questions about the extent to which the market (accurately) responds to the release of marketing information such as the ACSI.

\section{Sample}

We provide examination of the stock market's response to ACSI information by examining the three conditions discussed above in a single sample using standard econometric techniques from the accounting and finance literatures. We examine the valuation of ACSI information released from the first quarter of 1995 to the fourth quarter of 2006, inclusive. An important (and nontrivial) issue when dealing with ACSI data is how to handle scores for firms with both the parent and lower-level units or brands in the index, with the parent not represented but multiple divisions or brands appearing in the index, or with firms that merge (with or without the merged units that previously appeared in the ACSI continuing in the index). Few studies using ACSI data report how they deal with these circumstances, which can have significant implications for their results. We explicate our choices in the Appendix. Although all such 
choices are somewhat arbitrary, we attempt to minimize problems that can arise when studies simplistically link ACSI scores to company identifiers in common financial databases. ${ }^{4}$

The process reported in the Appendix yields 243 firms on COMPUSTAT, for a total of 1,795 firm-years with non-missing ACSI data. We use the ACSI's release date conventions to assign announcement dates to each firm-year. After requiring a lagged ACSI value (to compute changes in the scores), an ACSI announcement date prior to 2007, and market values on the CRSP daily file in the five days prior to the ACSI announcement, our final sample consists of 1,450 firm-year observations (substantially larger than the samples in related studies).

\section{ACSI Scores and Future Operating Performance}

Table 1 provides evidence on the first condition by examining the association between current ACSI scores and operating performance in the subsequent year. We examine three performance measures that the marketing literature suggests are related to customer satisfaction: revenues, profit margins, and return on assets (ROA). Prior research has shown that operating performance is very persistent (e.g., Penman, 1992; Fama and French, 2000). We therefore include the respective operating performance measures in the prior year as control variables. Similar to prior studies, we also include firm size (measured using the log of the firm's market capitalization), the firm's book-to-market ratio (an inverse proxy for the firm's growth opportunities), and indicators for the firm's industry membership as additional controls. Standard

\footnotetext{
${ }^{4}$ For example, early in the sample period ACSI reports scores for both Philip Morris and its subsidiary Kraft Foods. Naively matching both companies to financial databases would result in researchers double counting the parent's operating and stock performance. That is, on a given date there would be two identical operating performance and returns observations for Philip Morris, each linked to a different ACSI score. A similar problems arises when companies merge but ACSI continues to report scores for the individual entities (e.g., Compaq and HewlettPackard)
} 
errors are clustered by firm and by year to correct for both serial and cross-sectional dependence (see Gow et al., 2009).

With one exception, all three operating performance measures have significant, positive associations ( $\mathrm{p}<0.10$, two-tailed) with ACSI scores across the various models, even after controlling for past operating performance and the other control variables. The incremental $\mathrm{R}^{2}$ from the addition of the ACSI score (above the explanatory power of the control variables included in the models) ranges from $0.02 \%$ to $3.95 \%$. Although the incremental explanatory power is relatively small, the coefficients are economically significant for some of the tests. For example, the full ROA model indicates that a 10 point higher ACSI score is associated with a $1.3 \%$ higher return on assets in the next year. These results suggest that the ACSI measure is a significant, incremental indicator of future operational performance, and should therefore be priced by the market.

\section{Short-Term Stock Price Response to ACSI Changes}

We next examine the market's short-term response to the release of new ACSI scores. Even though ACSI levels appear to be predictive of future financial performance, the market may already impound this information in share prices, particularly given the strong autocorrelation in ACSI scores. As a result, the release of new ACSI scores may have little effect on share prices, even though customer satisfaction is value-relevant.

Fornell et al. (2006), for example, report no significant market reaction to the release of ACSI scores between the second quarter of 1999 and the third quarter of 2002 over short event windows (one to ten days after announcement). Surprisingly, Fornell et al.'s (2006) tests only examine the reaction to dichotomous positive or negative changes in ACSI, and do not examine 
the magnitude of the changes as is typical in accounting and finance event studies. In doing so, they treat very small positive (negative) changes the same as very large positive (negative) changes.

Since the conclusion that the market misprices customer satisfaction information rests on investors not quickly incorporating this information into share prices when initially released, we re-examine the short-term market reaction to new ACSI information. In contrast to Fornell et al. (2006), we follow the more typical accounting and finance practice of measuring the amount of new (or unexpected) information provided to the market using percentage changes in ACSI scores since the last release. ${ }^{5}$

Table 2 provides basic event study results for our sample. We form five portfolios based on the magnitude of percentage changes in ACSI scores. ${ }^{6}$ The median (mean) percentage ACSI change for the entire sample is $0 \%(-0.26 \%)$, reflecting the fact that the ACSI is not updated for every industry each quarter and the strong autocorrelation in ACSI scores. However, median percentage changes across the five portfolios range from $-4.71 \%$ to $4.11 \%$, suggesting that a simple split into positive and negative changes disguises significant variations in the new information being conveyed.

Panel A reports both average raw and market-adjusted buy-and-hold returns for the five trading days prior to the ACSI release. The market-adjusted returns control for changes in stock prices that are due to general market movements rather than to the release of ACSI information.

\footnotetext{
${ }^{5}$ The choice of a market "expectation model" is extremely important when investigating the market's valuation of information. As Sullivan et al. (1999) note, it is always possible to find excess returns if enough specifications are examined (i.e., aggressively using "data mining"). We use ACSI changes in all our valuation tests not only because this is the typical computation for the "unexpected" portion of a variable in accounting and finance, but also because it is less susceptible to the "data mining" critique. By using a percentage change measures, we are implicitly assuming decreasing returns to scale (i.e. a 5 unit increase in ACSI for a company with an ACSI score of 10 is more meaningful that a 5 unit increase in ACSI for a company with an ACSI score of 90).

${ }^{6}$ Using percentage changes as our measure of unexpected performance may tend to place firms with lower ASCI satisfaction levels in Quintile 5 (the quintile with the largest increases in satisfaction scores) because it is easier to achieve a larger percentage change when the denominator is smaller.
} 
If the release of ACSI information provides new information that is not anticipated by the market prior to the event date used in our analyses, we should see no significant association between changes in ACSI and returns during this pre-event period. Test statistics are clustered by event date to correct for cross-sectional dependence. The only portfolio that exhibits significant returns ( $\mathrm{p}<0.10$, two-tailed) is Quintile 5 (largest increases in ACSI) using raw returns, but none of the portfolio returns is significant using market-adjusted returns. The insignificant returns indicate that changes in ACSI do not predict returns in the days prior to the scores' release, consistent with these changes not being anticipated by the market over this period.

Panel B of Table 2 examines returns from the ACSI release date (day 0 ) to the fifth trading day after release. Raw returns are positive and significant in the three quintiles with the largest percentage increases in ACSI, with the returns becoming larger as the portfolios' ACSI changes increased. However, only the returns in Quintile 5 (those firms with the largest ACSI changes) are significant when market-adjusted returns are examined. The mean (median) percentage change in ACSI for firms in this quintile is 4.84\% (4.11\%). For these firms, the release of ACSI information is associated with a market-adjusted announcement period return of $1.3 \%$.

The results in Table 2 do not control for differences in risk that may account for the observed differences in returns. The omission of risk factors potentially leads to erroneous interpretations regarding the relation between ACSI measures and stock returns (e.g., Aksoy et al., 2008). We therefore conduct a more advanced event study using the Fama-French (1996) three-factor model commonly employed in accounting and finance research. This model estimates the excess return on a security (i.e. return in excess of the risk-free rate) over a given 
period as a function of risk factors associated with size $(S M B)$, value $(H M L)$, and covariance risk with the market risk premium $(M K T R F)^{7}$

We estimate the three-factor model for each of the ACSI percentage change quintiles over the 121-trading day period (approximately six months) centered on the scores' announcement. We include an indicator variable (denoted ANNC) that equals one on the announcement date and the following five-trading days (Panel A), 20-trading days (Panel B), 40trading days (Panel C), or 60-trading days (Panel D) to assess the market's reaction to the new ACSI information. Tuli and Bharadwaj (forthcoming) find that ACSI changes are associated with changes in firm risk. Consequently, we also include interactions between ANNC and each of the included risk-factors to examine whether the announcement influences the market's assessment of firm risk over the event periods.

The more advanced event study results are reported in Table 3. Consistent with the results in Table 2, the only portfolio exhibiting a significant association between stock returns and the announcement of ACSI changes is Quintile 5 (the largest ACSI changes). The coefficient on ANNC $\left(\alpha_{1}\right)$ is 0.15 over the 5-day event window and 0.10 over the 20-day window. In addition, for firms in Quintile 5 the interaction between ANNC and MKTRF $\left(\beta_{1}\right)$ is negative and significant in the five-day window. This suggests that that a large increase in ACSI scores (temporarily) lowers the market's risk assessment for these firms. However, as the event windows become longer, neither the announcement indicators nor the interaction terms are

\footnotetext{
${ }^{7}$ Fornell et al.'s (2006) event study uses abnormal returns from a market model that captures the MKTRF risk factor, but not the SMB or HML factors. All of our results are similar when we use the Carhart (1997) four-factor model that also includes a factor for stock return momentum.
} 
significant ( $\mathrm{p}<0.10$, two-tailed), suggesting that ACSI changes are quickly incorporated into share prices. ${ }^{8}$

In sum, the event study results indicate that the market does respond to the release of new ACSI information, but only when improvements are relatively large. Moreover, the market appears to quickly impound this information into share price, a result inconsistent with mispricing. This evidence differs from Fornell et al.'s (2006) conclusion (based on a shorter time period and different methodology) that ACSI information is not valued by the market at its release. ${ }^{9}$

\section{Long-Run Pricing of ACSI Information}

Finally, similar to Jacobson and Mizik (2009) and the earlier ACSI valuation studies, we conduct portfolio tests of the long-run valuation of ACSI information. An important issue in these tests is the expectations model used to assess the "new" information provided by the release of ACSI scores. Efficient markets theory argues that the market should only react to the unanticipated component of the information since the anticipated component should already be impounded in share price. The typical method used in accounting and finance research is examining the market's response to changes in a measure, particularly when the measure is highly autocorrelated like the ACSI. Examining ACSI changes rather than levels not only is

\footnotetext{
${ }^{8}$ One problem with our event study is that important information, other than the ACSI, is generally released during the same time period where the excess returns are computed. These information events have the potential to confound the results in Table 3. In an attempt to identify problematic observations, firms with excess returns outside the $1^{\text {st }}$ and $99^{\text {th }}$ percentiles or outside the $5^{\text {th }}$ and $95^{\text {th }}$ percentile were dropped from the analysis. The inferences are not changed after eliminating the impact of potentially problematic firms.

${ }^{9}$ We also follow Fornell et al. (2006) and repeat our event study tests grouping firms into "Increase in ACSI" and "Decrease in ACSI" portfolios. As in Fornell et al. (2006), when using these more crude groupings, we find no evidence of a significant announcement period reaction. In additional tests, we find no evidence that ACSI levels are associated with short-term returns, suggesting that expectations regarding satisfaction levels are already impounded by the market.
} 
more likely to capture the unexpected component of the information release, but also controls for correlated omitted variables that are related to both ACSI levels and stock returns.

In contrast, marketing studies of the ACSI's long-run valuation use a variety of unusual methods for forming portfolios, with relatively little explanation for these choices. Fornell et al. (2006), for example, form a trading rule that takes long positions in firms with scores above their competition and ACSI increases of two points or more, and short positions in firms with scores below the competition and declines of two points or more (with few short positions in most portfolios). ${ }^{10}$ Aksoy et al. (2008) form hedge portfolios that go long in firms with ACSI levels above the national average-adjusted mean score and increases in satisfaction scores, and short in firms with below adjusted-average mean satisfaction levels and declining scores. ${ }^{11}$ Jacobson and Mizik's (2009) study primarily relies on Aksoy et al.'s (2008) portfolio formation rules, though the authors also report that their (mixed) results are robust to other portfolio formation methods. The unusual mixture of satisfaction levels and arbitrary cutoffs in satisfaction changes used to form portfolios in these studies makes it difficult to conclude that a general trading rule that capitalizes on market mispricing of new ACSI information can be established. ${ }^{12}$

\footnotetext{
${ }^{10}$ Fornell et al. (2006) do not explain why they chose the two point cutoff. Their use of ACSI levels (relative to competitors) in forming portfolios also assumes that market participants do not accurately incorporate this information in current stock prices, even though past ACSI levels are highly autocorrelated with current satisfaction levels. One explanation for incorporating satisfaction levels in the analysis is the desire to examine whether customer satisfaction exhibits increasing or decreasing returns to scale, but this explanation is not used to motivate the authors' empirical tests. Despite the use of ACSI levels and the two point cutoff in forming their study's longrun investment portfolios, neither is used in the same paper's short-term event study (which only focuses on directional changes in ACSI scores).

${ }^{11}$ Aksoy et al. (2008) state that they adjust for national trends in ACSI scores to remove the impact of systematic economy-wide sentiment changes. However, it is not clear why this trend would not be value-relevant to investors if such sentiment changes have implications for cash flow or why controlling for the return on the market portfolio would not control for economy-wide sentiment changes. In addition, their simple directional change variables assume that the magnitude of changes is uninformative.

${ }^{12}$ Sullivan et al. (1999) cautions that return predictability may be an artifact of a large number of researchers' joint search for factors that predict returns. That is, researchers collectively consider a large number of trading rules, such that by chance a researcher may find what appears to be a highly successful trading rule that outperforms the benchmark strategy. They point out that when researchers evaluate multiple trading rules, testing the performance of a single rule in isolation, without taking into account the dependencies across the universe of trading rules being evaluated can lead to overstated inferences.
} 
When we employ more typical methods for modeling unexpected "innovations" in the ACSI using changes in the measure, we find no evidence of long-run mispricing. At each ACSI announcement date, we rank firms into quintiles using the current quarter's percentage change breakpoints. ${ }^{13}$ We then calculate both equal- and value-weighted portfolio returns to three trading strategies. Equal-weighted portfolio returns are computed by initially equal-weighting each stock, and value-weighted portfolio returns are computed by initially weighting each firm according to its market capitalization as of the close of trading on the trading day immediately preceding the ACSI announcement. ${ }^{14}$

The Long-Term strategy buys firms and holds the stock for 365 days. The Mid-Term strategy buys firms and holds the stock for 180 days. The Short-Term strategy buys firms and holds the stock until the next wave of ACSI scores is released (typically 3 months). For each strategy, portfolio returns are calculated assuming the investor bought stock at the closing price on the ACSI announcement date and held it until the earlier of the indicated period, or until the firm's ACSI score is changed, selling at the closing price on the respective day. ${ }^{15}$ We tabulate portfolio returns for each quintile, as well as for a zero-cost hedge portfolio that purchases stocks in the highest quintile and shorts those in the lowest quintile.

Table 4 presents average daily raw returns, average daily market-adjusted returns, and abnormal returns and factor-loadings from the Fama-French three-factor model. Although raw and market-adjusted returns are positive and significant in nearly all of the quintiles across the

\footnotetext{
${ }^{13}$ We compute breakpoints using the current quarter's ACSI information because the full distribution of changes in ACSI is not known to the market at the time of the ACSI announcement.

${ }^{14}$ Since small firms tend to be the most illiquid and thus most likely to be mispriced, power considerations for detecting mispricing suggest the use of equal weighed portfolios (see Brav et al., 2000). However, since small firms tend to be illiquid, observed returns will overstate earnable returns (see Blume and Stambaugh, 1983). In which case, a value-weighted portfolio will mitigate the concern that the returns to the trading rule are driven by returns to small illiquid stocks.

${ }^{15}$ We begin computing returns at the announcement date's closing price because investors would not know the ACSI score at the beginning of the day. Results are similar if we include the ACSI announcement date when computing the returns.
} 
three strategies, in no case are the returns statistically different between Quintile 1 (largest percentage reduction in ACSI) and Quintile 5 (largest percentage increase). More importantly, we find no significant abnormal returns $(\alpha)$ in the risk-adjusted three-factor model over any of the three trading horizons. ${ }^{16}$ Together with the significant short-term market reaction to large ACSI changes, the insignificant long-run portfolio test results suggest that the stock market quickly and efficiently incorporates the incremental information from ACSI updates in share prices.

Overall, long-run portfolio tests using more typical portfolio formation methods from the accounting and finance literatures provide no evidence of mispricing of ACSI information. The insignificant portfolio returns are more consistent with Jacobson and Mizik's (2009) finding that mispricing, if present at all, is limited to a small sample of firms, rather than with Fornell et al.'s (2006) and Aksoy et al.'s (2008) conclusions that significant long-run abnormal returns can be earned due to the market's short-term mispricing of ACSI measures. ${ }^{17}$

\section{Conclusions}

Our re-examination of the stock market's pricing of ACSI information suggests that customer satisfaction information, as captured in the ACSI, is value-relevant in that it is incrementally predictive of future operating performance, and could therefore be important to managers attempting to improve share price. We also find that the market reacts to the announcement of large increase in the ACSI quickly after information in the changes are released. However, our examination using well-established methods from the accounting and

\footnotetext{
${ }^{16}$ Our results are robust to restricting the sample to "internet firms" as in Jacobson and Mizik (2009) i.e., SIC codes 35,59 , and 73.

${ }^{17}$ When we repeat our analyses using the small subset of firms from the industries that Jacobson and Mizik (2009) include in their internet category, we find no evidence of mispricing for these firms in our sample using our methodology.
} 
finance literatures provides no evidence that ACSI information can be used to earn abnormal long-run returns.

While there are a number of reasons why our results may differ from those in earlier studies, they do suggest that any conclusions regarding the stock market's valuation of marketing information is quite sensitive to the sample and methodologies employed in the analyses. Researchers should be very explicit in articulating the justification for their methodological choices, and future studies should examine whether any findings of significant long-run abnormal returns hold over long periods of time, rather than reflecting potential short-term misunderstanding of new marketing information in evolving settings. Finally, studies examining the valuation of marketing information should examine the broad set of condition necessary (from the links between marketing metrics and operating performance through short-term and long-term market responses to the release of new information on these metrics) if the stock market's response to marketing initiatives and expenditures is to be fully understood. 


\section{References}

Aksoy, Lerzan. Bruce Cooil, Christopher Groening, Timothy L. Keiningham, and Atakan Yalcin (2008), "The Long Term Stock Market Valuation of Customer satisfaction," Journal of Marketing, 72 (4), 105-122.

Blume, Marshall and Robert Stambaugh (1983), "Biases in Computed Returns: An Application to the Size Effect," Journal of Financial Economics, 12: 387-404.

Brav, Alon, Christopher Geczy, and Paul Gompers (2000), "Is the Abnormal Return Following Equity Issuances Anomalous,” Journal of Financial Economics, 56: 209-249.

Carhart, Mark (1997), “On Persistence in Mutual Fund Performance,” Journal of Finance, 52 (1), 57-82.

Fama, Eugene and Kenneth R. French (1996), "Multifactor Explanations of Asset Pricing Anomalies," Journal of Finance, 51 (1), 55-87.

Fama, Eugene and Kenneth R. French (2000), "Forecasting Profitability and Earnings," Journal of Business 72 (1): 161-175.

Fornell, Claes, Sunil Mathas, Forest V. Morgenson III, and M.S. Krishnan (2006), “Customer Satisfaction and Stock Prices: High Returns, Low Risk," Journal of Marketing, 70 (1): 1-14.

Gow, Ian, Gaizka Ormazabal, and Daniel Taylor (2009), “Correcting for Cross-sectional and Time-series Dependence in Accounting Research. Working paper. Graduate School of Business, Stanford University.

Jacobson, Robert and Natalie Mizik (2009), "The Financial Markets and Customer Satisfaction: Re-examing Possible Financial Market Mispricing of Customer Satisfaction," Marketing Science, forthcoming.

Penman, Steven (1992), "Return to Fundamentals," Journal of Accounting, Auditing and Finance 7 (3): 465-483.

Sullivan, Ryan, Allan Timmermann, and Halbert White (1999), "Data-Snooping, Technical Trading Rule Performance, and the Bootstrap," Journal of Finance, 54 (5): 1647-1691

Tuli, Kapil R. and Sundar G. Bharadwaj (forthcoming), "Customer Satisfaction and Stock Returns Risk," Journal of Marketing, forthcoming. 


\section{Appendix}

Cleaning the ACSI data

Based on the name of each ACSI-entity we find a corresponding GVKEY on COMPUSTAT. We classify the ACSI-GVKEY link into one of five mutually exclusive categories:

0 - no record on COMPUSTAT

1 - clean match

2 - multiple divisions (ACSI entities) are assigned to a parent's GVKEY, the parent is not covered by ACSI over the period (e.g., Red Lobster and Olive Garden are owned by Darden Restaurants)

3 - a single division is assigned to the parent's GVKEY, the parent is covered by ACSI over the period (e.g. Kraft Foods was a subsidiary of Philip Morris prior to 2001)

4 - a single division is assigned to the parent's GVKEY, the parent is not covered by ACSI over the period (e.g., GEICO is a subsidiary of Berkshire Hathaway)

5 - merger w/overlapping ACSI observations (e.g., ACSI continues to report separate scores for Hewlett-Packard and Compaq post-merger)

6 - merger w/non-overlapping ACSI score data (e.g., ACSI data for US West ends 2000, ACSI data for Qwest Communications begins 2001)

In the event of a Category 0 or Category 3 match, the respective record is dropped. In the event of a Category 2 match, we average the ACSI scores across divisions. In the event of a Category 5 match, the overlapping records for the surviving entity are retained (e.g., Hewlett-Packard). This process results in matching the ACSI data to 243 unique GVKEYs (or company identifiers) on COMPUSTAT. 


\section{Table 1. Operating Performance}

This table shows results from regressions of future operating performance on ACSI scores and control variables. Following prior research we calculate cumulative operating performance over the four quarters ended subsequent to the announcement date. We use three measures of operating performance $\left(X_{t^{+}}\right)$, Revenue, Margin, and ROA. In our regressions we include controls for current period operating performance $\left(X_{t}\right)$, firm size (Size), the book-to-market ratio $(B M)$, and industry membership. Revenue is revenue (data\#2) over the next four quarters as a percent of current period total assets (data\#44), Margin is net income (data\#8) over the next four quarters scaled as a percent of revenue over the next four quarters, $R O A$ is net income over the next four quarters as a percent of current period total assets, Size is the log of market cap (data\#14* data\#61) for the quarter-end immediately prior to the ACSI announcement, and BM is book value (data \#59) scaled by market cap for the quarter-end immediately prior to the ACSI announcement. $t$-statistics appear in parentheses and are based on std. errors clustered by firm and by year to correct for serial and cross-sectional dependence respectively.

$$
X_{t+1}=\alpha_{0} A C S I_{t}+\alpha_{1} S_{Z I Z E_{t}}+\alpha_{2} B M_{t}+\alpha_{3} X_{t}+\boldsymbol{\theta} \text { Industry Effects }+\varepsilon_{t}
$$

where $X$ is Sales, Margin, or ROA.***,**,* indicates statistical significance at the $1 \%, 5 \%$ and $10 \%$ level (two-tailed), respectively.

\begin{tabular}{l|cccccc} 
& \multicolumn{6}{|c}{ Operating Performance Measure $\left(X_{t+1}\right)$} \\
Variable & Revenue & Revenue & Margin & Margin & ROA & ROA \\
\hline \multirow{2}{*}{ ACSI } & 0.27 & $0.49^{*}$ & $0.44^{* *}$ & $0.25^{*}$ & $0.27^{* * *}$ & $0.13^{* * *}$ \\
& $(0.36)$ & $(1.71)$ & $(2.38)$ & $(1.82)$ & $(3.65)$ & $(3.01)$ \\
SIZE & & $-4.57^{* * *}$ & & $1.57^{* * *}$ & & $0.66^{* * *}$ \\
& & $(-4.43)$ & & $(4.50)$ & & $(5.71)$ \\
$B M$ & & -3.44 & & -1.29 & & -0.64 \\
& & $(-1.36)$ & & $(-0.77)$ & & $(-0.83)$ \\
$X_{t}$ & & $0.82^{* * *}$ & & $0.34^{* *}$ & & $0.55^{* * *}$ \\
& & $(16.10)$ & & $(2.21)$ & & $(9.63)$ \\
\hline$F$ & 384.65 & 1927.22 & 11.82 & 26.43 & 58.20 & 257.57 \\
$\mathrm{R}^{2}$ & 45.19 & 87.22 & 14.50 & 34.40 & 17.90 & 51.30 \\
Incremental $\mathrm{R}^{2}$ & & & & & & \\
from ACSI & 0.02 & 0.07 & 2.64 & 1.63 & 3.95 & 0.86 \\
$\mathrm{~N}$ & 1,191 & 1,191 & 1,191 & 1,191 & 1,191 & 1,191
\end{tabular}




\section{Table 2. Basic Event Study}

This table shows buy-and-hold returns over the 11-day announcement period centered on the announcement date. To test for information leakage, we report buy-and-hold returns over the five trading day period prior to the announcement day in Panel A (i.e. $t=-5 \ldots-1$ ). To test for whether the market prices information in ACSI we report tests of market reaction using returns from $\mathrm{t}=0$ to +5 in Panel B. We rank all firms into quintiles based on the reported percentage change in ACSI. Market adjusted returns are computed relative to the CRSP value-weighted market portfolio. $t$-statistics based on std. errors clustered by event date to correct for crosssectional dependence appear in parentheses. $* * *, * *, *$ indicates statistical significance at the $1 \%$, $5 \%$ and $10 \%$ level (two-tailed), respectively. Sample of 1,450 firm-events.

Panel A. Buy and hold returns by Quintile of Percent Change in ACSI, $t=-5 \ldots-1$

\begin{tabular}{l|r|rrrrr} 
& & \multicolumn{5}{|c}{ Quintile } \\
\cline { 3 - 7 } & Pooled & \multicolumn{1}{|c}{1} & \multicolumn{1}{c}{2} & 3 & \multicolumn{1}{c}{5} \\
\hline Mean $\Delta$ ACSI (\%) & -0.26 & -5.59 & -1.93 & -0.23 & 1.64 & 4.84 \\
Median $\Delta$ ACSI (\%) & 0.00 & -4.71 & -1.56 & 0.00 & 1.37 & 4.11 \\
$\mathrm{~N}$ & 1450 & 285 & 296 & 296 & 287 & 286 \\
\hline & & & & & & \\
Raw Returns (\%) & 0.20 & 0.37 & -0.11 & 0.15 & 0.17 & $0.44^{*}$ \\
t-statistic & $(0.76)$ & $(0.81)$ & $(-0.26)$ & $(0.49)$ & $(0.49)$ & $(1.75)$ \\
& & & & & & \\
Market Adjusted (\%) & -0.07 & 0.13 & -0.41 & -0.40 & 0.09 & 0.27 \\
t-statistic & $(-0.26)$ & $(0.50)$ & $(-1.14)$ & $(-1.38)$ & $(0.24)$ & $(0.56)$
\end{tabular}

Panel B. Buy and hold returns by Quintile of Percent Change in ACSI, $t=0 \ldots+5$

\begin{tabular}{l|r|rrrrr} 
& & \multicolumn{5}{|c}{ Quintile } \\
\cline { 3 - 7 } & Pooled & \multicolumn{1}{|c}{1} & 2 & 3 & \multicolumn{1}{c}{} & \multicolumn{1}{c}{5} \\
\hline Mean $\Delta$ ACSI (\%) & -0.26 & -5.59 & -1.93 & -0.23 & 1.64 & 4.84 \\
Median $\Delta$ ACSI (\%) & 0.00 & -4.71 & -1.56 & 0.00 & 1.37 & 4.11 \\
$\mathrm{~N}$ & 1450 & 285 & 296 & 296 & 287 & 286 \\
\hline & & & & & & \\
Raw Returns (\%) & $0.83^{* * *}$ & 0.55 & 0.44 & $0.81 * *$ & $0.86^{* *}$ & $1.49 * * *$ \\
t-statistic & $(2.74)$ & $(1.49)$ & $(1.19)$ & $(2.00)$ & $(2.17)$ & $(3.51)$ \\
& & & & & & \\
Market Adjusted (\%) & 0.47 & 0.13 & 0.20 & 0.25 & 0.49 & $1.30^{* * *}$ \\
t-statistic & $(1.52)$ & $(0.33)$ & $(0.73)$ & $(0.56)$ & $(1.14)$ & $(2.68)$
\end{tabular}




\section{Table 3. Advanced Event Study}

This table show results from estimating the three factor model by percent change quintile over the 121 trading day period, approximately 6 months, centered on the announcement $(t=$ $60 \ldots 60)$. We report results including an indicator variable $A N N C$ equal one on the day of the announcement and the next 5 trading days (Panel A), 20 trading days (Panel B), 40 trading days (Panel C), and 60 trading days (Panel D). We interact $A N N C$ with each of the included riskfactors to test for a difference in risk over the respective announcement period. $t$-statistics based on standard errors clustered by date to correct for cross-sectional dependence appear in parentheses. Sample of 1,450 firm-events.

$$
\begin{aligned}
R_{t}-R_{f t}= & \alpha_{0}+\alpha_{1} A N N C_{t}+\beta_{0} M K T R F_{t}+\beta_{1} A N N C_{t} * M K T R F_{t} \\
& +s_{0} S M B_{t}+s_{1} A N N C_{t} * S M B_{t}+h_{0} H M L_{t}+h_{1} A N N C_{t} * H M L_{t}+\varepsilon_{t}, \quad t=-60 \ldots 60
\end{aligned}
$$

\begin{tabular}{|c|c|c|c|c|c|c|c|c|c|c|}
\hline & \multicolumn{2}{|c|}{ Quintile 1} & \multicolumn{2}{|c|}{ Quintile 2} & \multicolumn{2}{|c|}{ Quintile 3} & \multicolumn{2}{|c|}{ Quintile 4} & \multicolumn{2}{|c|}{ Quintile 5} \\
\hline & coeff. & $\mathrm{t}$ & coeff. & $\mathrm{t}$ & coeff. & $\mathrm{t}$ & coeff. & $\mathrm{t}$ & coeff. & $\mathrm{t}$ \\
\hline$\alpha_{0}$ & -0.01 & $(-1.44)$ & -0.01 & $(-0.31)$ & 0.01 & $(0.37)$ & 0.01 & $(0.10)$ & 0.01 & $(0.42)$ \\
\hline$\alpha_{1}$ & 0.05 & $(0.84)$ & 0.02 & $(0.49)$ & 0.03 & $(0.47)$ & 0.04 & $(0.60)$ & 0.15 & (2.11) \\
\hline$\beta_{0}$ & 1.00 & (13.43) & 0.96 & (19.72) & 0.89 & (12.90) & 0.93 & (13.84) & 1.02 & (19.16) \\
\hline$\beta_{1}$ & -0.11 & $(-0.95)$ & 0.00 & $(-0.04)$ & -0.07 & $(-1.32)$ & -0.02 & $(-0.30)$ & -0.19 & $(-2.10)$ \\
\hline$s_{0}$ & -0.14 & $(-2.34)$ & -0.12 & $(-1.75)$ & -0.14 & $(-2.34)$ & -0.14 & $(-2.09)$ & -0.07 & $(-0.81)$ \\
\hline$s_{1}$ & -0.20 & $(-1.86)$ & -0.06 & $(-0.60)$ & -0.10 & $(-0.9$ & -0.01 & $(-0$. & -0.11 & $(-1.08)$ \\
\hline$h_{0}$ & 0.61 & $(4.32)$ & 0.49 & $(6.36)$ & 0.50 & $(4.04)$ & 0.62 & (4.48) & 0.69 & (5.11) \\
\hline$h_{1}$ & -0.03 & $(-0.15)$ & -0.06 & $(-0.42)$ & 0.11 & $(0.89)$ & -0.02 & $(-0.11)$ & -0.15 & $(-1.08)$ \\
\hline$F$ & & & & 09 & & .87 & & .82 & & \\
\hline$R^{2}$ & & & & 47 & & .07 & & .06 & & 97 \\
\hline
\end{tabular}

\section{Panel A. 5-Day Announcement Period}

\begin{tabular}{|c|c|c|c|c|c|c|c|c|c|c|}
\hline & \multicolumn{2}{|c|}{ Quintile 1} & \multicolumn{2}{|c|}{ Quintile 2} & \multicolumn{2}{|c|}{ Quintile 3} & \multicolumn{2}{|c|}{ Quintile 4} & \multicolumn{2}{|c|}{ Quintile 5} \\
\hline & coeff. & $\mathrm{t}$ & coeff. & $\mathrm{t}$ & coeff. & $\mathrm{t}$ & coeff. & $\mathrm{t}$ & coeff. & $\mathrm{t}$ \\
\hline$\alpha_{0}$ & -0.01 & $(-1.77)$ & -0.01 & $(-0.58)$ & 0.01 & $(0.31)$ & 0.01 & $(0.01)$ & -0.01 & $(-0.09)$ \\
\hline$\alpha_{1}$ & 0.01 & $(1.06)$ & 0.01 & $(0.81)$ & 0.01 & $(0.24)$ & 0.02 & $(0.36)$ & 0.10 & (3.18) \\
\hline$\beta_{0}$ & 0.99 & (12.58) & 0.93 & $(20.34)$ & 0.89 & (13.03) & 0.91 & (13.28) & 1.01 & (18.21) \\
\hline$\beta_{1}$ & 0.01 & $(0.18)$ & 0.15 & $(1.74)$ & 0.04 & $(0.58)$ & 0.09 & $(1.21)$ & 0.01 & $(0.19)$ \\
\hline$s_{0}$ & -0.12 & $(-2.16)$ & -0.12 & $(-1.96)$ & -0.14 & $(-2.31)$ & -0.14 & $(-1.97)$ & -0.05 & $(-0.59)$ \\
\hline$s_{1}$ & -0.14 & $(-1.97)$ & -0.01 & $(-0.14)$ & -0.04 & $(-0.43)$ & -0.02 & $(-0.22)$ & -0.14 & $(-1.25)$ \\
\hline$h_{0}$ & 0.60 & $(3.96)$ & 0.46 & $(5.57)$ & 0.47 & $(3.95)$ & 0.59 & $(4.40)$ & 0.68 & $(5.00)$ \\
\hline$h_{1}$ & 0.04 & $(0.27)$ & 0.17 & (1.59) & 0.24 & $(2.26)$ & 0.20 & (1.90) & 0.06 & $(0.61)$ \\
\hline$F$ & & & & 5.56 & & .07 & & .67 & & \\
\hline$R^{2}$ & & & & & & .10 & & .09 & & \\
\hline
\end{tabular}

Panel B. 20-Day Announcement Period 
Table 3. Advanced Event Study (Cont'd)

Panel C. 40-Day Announcement Period

\begin{tabular}{l|rrrrrrrrrr} 
& \multicolumn{2}{|c}{ Quintile 1 } & \multicolumn{2}{c}{ Quintile 2 } & \multicolumn{2}{c}{ Quintile 3 } & \multicolumn{2}{c}{ Quintile 4 } & \multicolumn{2}{c}{ Quintile 5 } \\
& coeff. & \multicolumn{1}{c}{$\mathrm{t}$} & \multicolumn{1}{c}{ coeff. } & \multicolumn{1}{c}{$\mathrm{t}$} & \multicolumn{1}{c}{ coeff. } & \multicolumn{1}{c}{$\mathrm{t}$} & coeff. & \multicolumn{1}{c}{$\mathrm{t}$} & \multicolumn{1}{c}{ coeff. } & \multicolumn{1}{c}{ t } \\
\hline$\alpha_{0}$ & -0.02 & $(-1.57)$ & 0.01 & $(0.13)$ & 0.01 & $(0.59)$ & 0.02 & $(1.00)$ & 0.01 & $(0.45)$ \\
$\alpha_{1}$ & 0.01 & $(0.34)$ & -0.02 & $(-0.54)$ & -0.02 & $(-0.61)$ & -0.04 & $(-1.36)$ & 0.02 & $(0.72)$ \\
$\beta_{0}$ & 0.98 & $(13.64)$ & 0.93 & $(17.43)$ & 0.87 & $(11.56)$ & 0.87 & $(13.08)$ & 0.99 & $(16.39)$ \\
$\beta_{1}$ & 0.06 & $(0.79)$ & 0.10 & $(1.54)$ & 0.07 & $(1.09)$ & 0.18 & $(3.17)$ & 0.07 & $(1.54)$ \\
$s_{0}$ & -0.14 & $(-3.09)$ & -0.13 & $(-2.03)$ & -0.16 & $(-2.84)$ & -0.16 & $(-2.11)$ & -0.06 & $(-0.61)$ \\
$s_{1}$ & 0.01 & $(0.17)$ & 0.01 & $(0.10)$ & 0.06 & $(0.82)$ & 0.08 & $(0.97)$ & -0.03 & $(-0.27)$ \\
$h_{0}$ & 0.55 & $(3.46)$ & 0.42 & $(5.12)$ & 0.44 & $(3.99)$ & 0.50 & $(4.18)$ & 0.67 & $(5.40)$ \\
$h_{1}$ & 0.19 & $(1.35)$ & 0.20 & $(2.16)$ & 0.19 & $(1.43)$ & 0.35 & $(3.69)$ & 0.06 & $(0.51)$ \\
\hline$F$ & \multicolumn{2}{|c}{91.09} & 82.06 & 36.37 & 45.58 & 146.99 \\
$R^{2}$ & 13.54 & 16.51 & 11.09 & 16.21 & 11.96
\end{tabular}

Panel D. 60-Day Announcement Period

\begin{tabular}{c|rrrrrrrrrr} 
& \multicolumn{2}{|c}{ Quintile 1 } & \multicolumn{2}{c}{ Quintile 2 } & \multicolumn{2}{c}{ Quintile 3 } & \multicolumn{2}{c}{ Quintile 4 } & \multicolumn{2}{c}{ Quintile 5 } \\
& coeff. & \multicolumn{1}{c}{ t } & \multicolumn{1}{c}{ coeff. } & \multicolumn{1}{c}{$\mathrm{t}$} & \multicolumn{1}{c}{ coeff. } & \multicolumn{1}{c}{ coeff. } & \multicolumn{1}{c}{$\mathrm{t}$} & \multicolumn{1}{c}{ coeff. } & \multicolumn{1}{c}{$\mathrm{c}$} \\
\hline$\alpha_{0}$ & -0.01 & $(-0.88)$ & -0.01 & $(-0.21)$ & 0.01 & $(0.30)$ & 0.01 & $(0.68)$ & 0.02 & $(0.83)$ \\
$\alpha_{1}$ & -0.01 & $(-0.74)$ & 0.01 & $(0.13)$ & 0.01 & $(0.02)$ & -0.01 & $(-0.78)$ & -0.01 & $(-0.06)$ \\
$\beta_{0}$ & 0.94 & $(17.58)$ & 0.91 & $(15.15)$ & 0.83 & $(10.13)$ & 0.85 & $(11.12)$ & 0.97 & $(14.68)$ \\
$\beta_{1}$ & 0.10 & $(1.11)$ & 0.10 & $(1.74)$ & 0.12 & $(2.03)$ & 0.15 & $(2.47)$ & 0.09 & $(1.25)$ \\
$s_{0}$ & -0.13 & $(-2.98)$ & -0.14 & $(-1.98)$ & -0.16 & $(-2.60)$ & -0.19 & $(-2.13)$ & -0.13 & $(-1.26)$ \\
$s_{1}$ & -0.03 & $(-0.34)$ & 0.03 & $(0.38)$ & 0.03 & $(0.35)$ & 0.09 & $(1.03)$ & 0.12 & $(1.13)$ \\
$h_{0}$ & 0.57 & $(3.56)$ & 0.40 & $(4.22)$ & 0.43 & $(3.78)$ & 0.52 & $(3.98)$ & 0.62 & $(5.64)$ \\
$h_{1}$ & 0.08 & $(0.49)$ & 0.17 & $(1.88)$ & 0.15 & $(1.25)$ & 0.20 & $(1.77)$ & 0.13 & $(0.99)$ \\
\hline$F$ & 115.90 & 83.71 & 47.97 & 43.01 & 82.66 \\
$R^{2}$ & 13.54 & 16.51 & 11.10 & 16.15 & 11.97
\end{tabular}




\section{Table 4. Portfolio Analysis}

Estimated returns to trading strategies based on innovations in ACSI. At each ACSI announcement date firms are ranked into quintiles using the current quarter's breakpoints. The Long-Term strategy (Panel A) buys firms and holds them for 365 days. The Mid-Term strategy (Panel B) buys firms and holds them for 180 days. The Short-Term strategy (Panel C) buys firms and holds them until the next wave of ACSI scores is released (typically 3 months). Average daily portfolio returns (\%), market adjusted portfolio returns $(\%)$, and coefficient estimates from the Fama-French three factor model are reported. $t$-statistics appear in parentheses.

Sample of 1,450 firm-events.

Panel A. Long-Term Strategy Returns

\begin{tabular}{lccccc|c} 
& \multicolumn{9}{c|}{ Equal-weighted Quintile Portfolio Returns } & Hedge \\
& 1 & 2 & 3 & 4 & 5 & Q5-Q1 \\
\cline { 2 - 7 } Raw & 0.06 & 0.05 & 0.05 & 0.06 & 0.06 & -0.00 \\
t-stat & $(3.47)$ & $(2.95)$ & $(2.78)$ & $(3.13)$ & $(3.34)$ & $(-0.14)$ \\
Mkt Adj. & 0.05 & 0.04 & 0.03 & 0.04 & 0.05 & -0.00 \\
t-statistic & $(3.79)$ & $(3.05)$ & $(2.52)$ & $(2.95)$ & $(3.67)$ & $(-0.14)$ \\
\hline$\alpha$ & 0.01 & -0.002 & -0.01 & -0.003 & 0.002 & -0.008 \\
t-stat & $(0.95)$ & $(-0.15)$ & $(-0.90)$ & $(-0.30)$ & $(0.21)$ & $(-0.64)$ \\
$\beta$ & 0.92 & 0.93 & 0.91 & 0.93 & 0.99 & 0.07 \\
t-stat & $(61.89)$ & $(65.72)$ & $(58.44)$ & $(61.02)$ & $(58.86)$ & $(3.99)$ \\
$s$ & -0.14 & -0.14 & -0.16 & -0.08 & -0.03 & 0.11 \\
t-stat & $(-6.30)$ & $(-5.98)$ & $(-6.68)$ & $(-3.62)$ & $(-1.12)$ & $(4.69)$ \\
$h$ & 0.49 & 0.51 & 0.60 & 0.65 & 0.63 & 0.14 \\
t-stat & $(17.34)$ & $(18.28)$ & $(20.59)$ & $(21.87)$ & $(20.10)$ & $(4.35)$
\end{tabular}

\begin{tabular}{ccccc|c}
\hline \multicolumn{7}{c|}{ Value-weighted Quintile Portfolio Returns } & Hedge \\
1 & 2 & 3 & 4 & 5 & Q5-Q1 \\
\hline 0.04 & 0.04 & 0.05 & 0.05 & 0.06 & 0.02 \\
$(1.95)$ & $(1.99)$ & $(2.54)$ & $(2.39)$ & $(2.42)$ & $(0.83)$ \\
0.02 & 0.03 & 0.03 & 0.03 & 0.04 & 0.02 \\
$(1.60)$ & $(1.84)$ & $(2.40)$ & $(2.290$ & $(2.87)$ & $(0.83)$ \\
\hline-0.01 & -0.01 & 0.00 & 0.00 & 0.01 & 0.02 \\
$(-0.40)$ & $(-0.52)$ & $(0.15)$ & $(0.02)$ & $(0.70)$ & $(0.76)$ \\
0.85 & 0.93 & 0.88 & 0.91 & 0.97 & 0.12 \\
$(45.52)$ & $(53.88)$ & $(49.89)$ & $(48.35)$ & $(49.93)$ & $(4.08)$ \\
-0.34 & -0.36 & -0.38 & -0.40 & -0.26 & 0.08 \\
$(-12.54)$ & $(-13.19)$ & $(-15.09)$ & $(-13.96)$ & $(-9.42)$ & $(2.16)$ \\
0.22 & 0.27 & 0.35 & 0.35 & 0.08 & -0.14 \\
$(5.77)$ & $(7.48)$ & $(9.96)$ & $(9.45)$ & $(2.12)$ & $(-2.32)$
\end{tabular}


Table 4. Portfolio Analysis (Cont'd)

\section{Panel B. Mid-Term Strategy Returns}

\begin{tabular}{lccccc|c} 
& \multicolumn{9}{c|}{ Equal-weighted Quintile Portfolio Returns } & Hedge \\
& 1 & 2 & 3 & 4 & 5 & Q5-Q1 \\
\cline { 2 - 7 } Raw & 0.06 & 0.05 & 0.06 & 0.07 & 0.05 & -0.01 \\
t-stat & $(2.88)$ & $(2.46)$ & $(2.69)$ & $(3.25)$ & $(2.50)$ & $(-0.30)$ \\
Mkt Adj. & 0.04 & 0.03 & 0.04 & 0.05 & 0.03 & -0.01 \\
t-stat & $(2.74)$ & $(2.43)$ & $(2.43)$ & $(3.00)$ & $(2.33)$ & $(-0.30)$ \\
\hline$\alpha$ & 0.003 & -0.003 & -0.01 & 0.01 & -0.006 & -0.01 \\
t-stat & $(0.22)$ & $(-0.24)$ & $(-0.39)$ & $(0.49)$ & $(-0.45)$ & $(-0.57)$ \\
$\beta$ & 0.96 & 0.94 & 0.98 & 0.95 & 1.04 & 0.08 \\
t-stat & $(29.20)$ & $(44.13)$ & $(26.47)$ & $(39.83)$ & $(28.92)$ & $(2.57)$ \\
$s$ & -0.14 & -0.17 & -0.14 & -0.06 & -0.07 & 0.07 \\
t-stat & $(-4.74)$ & $(-4.84)$ & $(-3.70)$ & $(-1.97)$ & $(-1.63)$ & $(1.89)$ \\
$h$ & 0.59 & 0.49 & 0.70 & 0.69 & 0.68 & 0.09 \\
t-stat & $(10.27)$ & $(11.81)$ & $(11.94)$ & $(15.26)$ & $(11.13)$ & $(1.47)$
\end{tabular}

\begin{tabular}{|c|c|c|c|c|c|}
\hline \multicolumn{5}{|c|}{ Value-weighted Quintile Portfolio Returns } & \multirow{2}{*}{$\begin{array}{l}\text { Hedge } \\
\text { Q5-Q1 }\end{array}$} \\
\hline 1 & 2 & 3 & 4 & 5 & \\
\hline 0.04 & 0.04 & 0.07 & 0.05 & 0.06 & 0.02 \\
\hline (1.74) & (1.63) & $(2.90)$ & (1.99) & $(2.48)$ & $(0.82)$ \\
\hline 0.03 & 0.02 & 0.05 & 0.03 & 0.05 & 0.02 \\
\hline$(1.30)$ & $(1.25)$ & $(2.72)$ & $(1.63)$ & $(2.40)$ & $(0.82)$ \\
\hline-0.01 & -0.01 & 0.01 & -0.01 & 0.01 & 0.02 \\
\hline$(-0.42)$ & $(-0.35)$ & $(0.91)$ & $(-0.40)$ & $(0.64)$ & $(0.75)$ \\
\hline 0.91 & 0.91 & 0.91 & 0.96 & 0.99 & 0.08 \\
\hline (37.11) & (35.69) & (38.37) & $(34.50)$ & $(32.15)$ & $(1.86)$ \\
\hline-0.32 & -0.36 & -0.41 & -0.31 & -0.31 & 0.01 \\
\hline$(-8.35)$ & $(-8.95)$ & $(-10.93)$ & $9-8.33)$ & $(-6.59)$ & (18) \\
\hline 0.40 & 0.20 & 0.47 & 0.48 & 0.35 & -0.05 \\
\hline$(5.78)$ & $(3.57)$ & $(9.73)$ & $(9.30)$ & $(5.03)$ & $(-0.47)$ \\
\hline
\end{tabular}


Table 4. Portfolio Analysis (Continued)

\section{Panel C. Short-Term Strategy Returns}

\begin{tabular}{lccccc|c} 
& \multicolumn{9}{c|}{ Equal-weighted } & \multicolumn{3}{c|}{ Quintile } & Portfolio Returns & Hedge \\
& 1 & 2 & 3 & 4 & 5 & Q5-Q1 \\
\cline { 2 - 7 } Raw & 0.06 & 0.03 & 0.05 & 0.07 & 0.07 & 0.01 \\
t-stat & $(2.41)$ & $(1.05)$ & $(2.13)$ & $(2.44)$ & $(2.30)$ & $(0.13)$ \\
Mkt Adj. & 0.05 & 0.01 & 0.03 & 0.05 & 0.05 & 0.01 \\
t-stat & $(2.13)$ & $(0.50)$ & $(1.78)$ & $(2.19)$ & $(2.09)$ & $(0.13)$ \\
\hline$\alpha$ & 0.003 & -0.03 & -0.01 & 0.003 & 0.007 & 0.004 \\
t-stat & $(0.15)$ & $(-1.35)$ & $(-0.35)$ & $(0.14)$ & $(0.30)$ & $(0.15)$ \\
$\beta$ & 1.02 & 0.98 & 1.01 & 1.08 & 1.06 & 0.04 \\
t-stat & $(28.45)$ & $(30.72)$ & $(29.88)$ & $(26.53)$ & $(20.77)$ & $(0.86)$ \\
$s$ & -0.05 & -0.08 & -0.14 & -0.04 & -0.07 & -0.01 \\
t-stat & $(-1.20)$ & $(-1.88)$ & $(-2.92)$ & $(-0.86)$ & $(-1.07)$ & $(-0.19)$ \\
$h$ & 0.65 & 0.46 & 0.67 & 0.74 & 0.57 & -0.07 \\
t-stat & $(8.74)$ & $(6.98)$ & $(11.06)$ & $(9.78)$ & $(6.18)$ & $(-0.80)$
\end{tabular}

\begin{tabular}{|c|c|c|c|c|c|}
\hline \multicolumn{5}{|c|}{ Value-weighted Quintile Portfolio Returns } & \multirow{2}{*}{$\begin{array}{l}\text { Hedge } \\
\text { Q5-Q1 }\end{array}$} \\
\hline 1 & 2 & 3 & 4 & 5 & \\
\hline 0.06 & 0.04 & 0.06 & 0.06 & 0.08 & 0.02 \\
\hline$(2.13)$ & (1.21) & $(2.15)$ & $(2.04)$ & $(2.67)$ & $(0.72)$ \\
\hline 0.04 & 0.02 & 0.04 & 0.04 & 0.06 & 0.02 \\
\hline (1.77) & $(0.77)$ & $(1.86)$ & $(1.71)$ & $(2.49)$ & $(0.72)$ \\
\hline 0.01 & -0.02 & 0.00 & -0.004 & 0.02 & 0.01 \\
\hline$(0.26)$ & $(-0.62)$ & $(0.02)$ & $(-0.17)$ & $(0.78)$ & $(0.44)$ \\
\hline 0.93 & 0.98 & 1.02 & 1.04 & 1.06 & 0.13 \\
\hline$(26.70)$ & (24.99) & $(26.35)$ & $(25.81)$ & (21.73) & $(2.43)$ \\
\hline-0.26 & -0.28 & -0.29 & -0.24 & -0.20 & 0.06 \\
\hline$(-5.43)$ & $(-5.37)$ & $(-5.97)$ & $(-5.16)$ & $(-3.43)$ & $(0.85)$ \\
\hline 0.48 & 0.33 & 0.61 & 0.67 & 0.63 & 0.15 \\
\hline$(6.23)$ & (3.94) & $(8.61)$ & $(8.96)$ & (7.40) & (1.48) \\
\hline
\end{tabular}

